\section{Severe war trauma and post-traumatic stress disorder in adolescents with sensory impairments: a cross-sectional study}

\author{
Khuzama Hijal Shaar \\ Department of Medical Sciences, Faculty \\ of Medicine and Medical Sciences, Holy \\ Spirit University of Kaslik, Lebanon
}

\section{Abstract}

A paucity of studies of the psychological status of adolescents with sensory impairments in political conflict areas is noted. This study was set up to examine the exposure of adolescents with sensory impairments (ASIs) to severe war trauma and development of posttraumatic stress disorder (PTSD) as compared to their able-bodied peers (ABPs). It also answers the question whether their impairments have made them more resilient in facing traumatic events. A cross-sectional study of all ASIs attending special schools in three administrative districts in Lebanon $(\mathrm{n}=166)$ as well as a group of 166 age and sex-matched ABPs from neighboring schools was conducted. The Post Traumatic Stress Reaction Checklist for children (PTSRC) was used to assess exposure to severe trauma, PTSD and their determinants. ASIs reported a lower exposure to severe traumatic events (24.1\%) as compared to their ABPs (69.9\%), and risk factors for their exposure were an older age group, a fatherless family, and severe visual impairment. Prevalence rates for PTSD were similar in the two study groups $(17.5 \%$ and $16.4 \%)$. Younger ASIs were at a significantly higher risk of developing PTSD. Lower exposure to trauma among ASIs points to the more sheltered life that they lead. Given the same exposure as ABPs, similar rates of PTSD are noted among the two study groups. This may indicate that having a sensory impairment may protect from PTSD due to decreased exposure to severe trauma and not due to increased resilience of subjects.

\section{Introduction}

People in Lebanon endured a series of wars such as the endemic war of 1976-1990 in the last decades. This war was characterized by intermittent and unpredictable bouts of violence that included street fighting, indiscriminant shelling of residential areas, sniping, kidnapping and torture, and massive displace- ment waves. These war events were likened to the episodes of a chronic disease as they were uncontrollable, unexpected when they flared and abated. ${ }^{1}$ Researchers have noted that pathologic stress syndromes such as post traumatic stress disorder (PTSD), which were closely identified in war veterans, were also experienced by individuals in the community. ${ }^{2,3}$ Adolescents are a vulnerable group in face of war adversities. A plethora of research exists describing mental health problems of children and adolescents in areas of armed conflict in the Middle East such as studies conducted in Lebanon, ${ }^{4-8}$ Iraq, ${ }^{9-12}$ Kuwait, ${ }^{13}$ Israel,14,15 and the Palestinian territories to name a few. ${ }^{16-20}$

Little is known about the effects of exposure to war trauma in people with sensory impairments. To harbor an impairment means to be presented with every day problems related to the impairment itself, in addition to coping with negative social response. Adolescents living with impairments are faced by social stigma, prejudices and discrimination. ${ }^{21}$ A social distance places them in social isolation from their able-bodied peers. ${ }^{22}$ Under conditions of extreme war stress, the question is whether people with impairments have indeed become more resilient than their able-bodied peers, and hence would fare better under stressful conditions.

Studies of PTSD among people with impairments in general are scanty. A national study in Afghanistan included persons with sensory and physical impairments and assessed their disabilities including disability in their social roles. ${ }^{23}$ Lower PTSD prevalence rates were noted among the disabled group of young adults sub-sample aged 15-34 years as compared to the able-bodied group (24.2\% and $39.9 \%$ respectively). To our knowledge, no other similar studies were found. As such, this study was set up to answer the following questions: i) What is the frequency and what are the risk factors for exposure to severe traumatic events in adolescents with sensory impairments compared to their able-bodied peers? ii) Given exposure to severe traumatic events, how do these two groups compare regarding development of PTSD and what are their risk factors for PTSD inception?

\section{Materials and Methods}

\section{Subjects and procedure}

The study information was extracted from the study Mental Health of Adolescents with Sensory Disabilities in Times of War in Lebanon (Shaar KH, unpublished data). Data for that study were collected at the end of the Lebanese Civil War (1991-1992). All institutions that
Correspondence: Khuzama Hijal Shaar Department of Medical Sciences, Faculty of Medicine and Medical Sciences, Holy Spirit University of Kaslik, Kaslik, Lebanon.

Tel. + 961.3284675 - Fax: + 961.1614113

E-mail: edumh105@hotmail.com

Key words: post traumatic stress disorder, adolescents, disability, war trauma, Lebanon.

Acknowledgments: the author wishes to thank Dr. Haroutune Armenian for his review of the manuscript.

Funding: this study was funded in part by the Research Board of the American University of Beirut, Lebanon.

Conflict of interests: the author declares no potential conflict of interests.

Received for publication: 13 November 2012.

Revision received: 20 December 2012.

Accepted for publication: 27 December 2012.

This work is licensed under a Creative Commons Attribution NonCommercial 3.0 License (CC BYNC 3.0).

(C) Copyright K.H. Shaar et al., 2013

Licensee PAGEPress, Italy

Health Psychology Research 2013; 1:e16

doi:10.4082/hpr.2013.e16

offered educational services to individuals with sensory impairments in three Administrative Sectors (Muhafazat) in Lebanon were identified, contacted and informed about the study (11 institutions). All adolescents aged 10 to 20 years enrolled in these schools $(n=232)$ were invited to participate in the study. One institution in Mount Lebanon refused to cooperate. A total of 199 adolescents with impairments were included in the study for a response rate of $85.8 \%$. Further, 166 adolescents with impairments agreed to participate in the study (response rate: $83.4 \%$ ). For each institution that cared for adolescents with impairments, a neighborhood school similar to that institution on mode of tuition payment (private $v s$. state funded) was selected at random, and these schools were also contacted and informed about the study. An age ( \pm 3 years) and sex-matched able-bodied adolescent was selected from each school to constitute a comparison group for the disabled group. Data were collected in the school setting under the supervision of trained university students.

\section{Ethical considerations}

At the time of data collection, the author received the approval of the University Research Board, American University of 
Beirut, the Ministry of Education, and the respective schools that cared for persons with sensory disabilities. In addition, verbal consent was obtained from each participant after being informed of the study and its anonymous nature.

\section{Instruments}

The study questionnaire included questions about disability characteristics, age, sex, father's occupation, exposure to severe trauma, and PTSD. Disability characteristics were provided by teachers of the study subjects. Socio-demographic information was elicited by simple questions. Occupation of father was the basis for determining the family's social class (SC) according to the British Registrar General's Classification of Occupations. ${ }^{24}$ This classification was adapted earlier for use in Lebanon. ${ }^{25}$ In this classification, SC I is professional work, SC II is managerial work, SC III NM is skilled non-manual work, SC IIIM is skilled manual labor, SC IV is semi skilled labor and SC V is unskilled labor. Social class was also bracketed into two groups: a non-manual work group comprising social classes I,II, and IIINM, and a manual work group comprising classes IIIM, IV and V.

PTSD was assessed by the Post Traumatic Stress Reaction Checklist for Children (PTSRC) devised by Macksoud et al. ${ }^{26}$ The PTSRC is designed as a structured interview schedule for children based on the DSM III-R diagnosis of PTSD. ${ }^{27}$ It measures PTSD symptoms in relation to one war trauma that he or she feel as the most disturbing for him or her, and measures PTSD symptoms in relation to that one trauma. The PTSDRC consists of 14 items that are rated on a dichotomous basis and that cover the three main domains of PTSD, namely i) experiencing the event, ii) avoidance and decreased involvement with the environment, and iii) increased state of alertness. Consequently, the DSMIII-R criteria for identifying a case of PTSD were used: i) exposure to a traumatic event, and ii) at least one symptom of re-experiencing the event, and iii) at least three symptoms of avoidance, and iv) at least two symptoms of increased arousal. A valid and reliable Arabic version of this scale was also devised by Macksoud et al. ${ }^{26}$

\section{Statistical analyses}

Simple frequency distributions about disability characteristics of the group with sensory impairments and selected socio-demographic characteristics of the two study groups were generated. The distribution of the two study groups by type of most severe event that they experienced was also generated. In a next step, cross-tabulations of the relationship of the study risk factors to exposure to traumatic events and to PTSD were generated. Risk factors were age ( $\geq 13$ years $v s .<13$ years), sex (male $v s$. female), identity of head of household (father $v s$. other), social class of head of household (manual vs. non-manual), and region of residence (Greater Beirut vs. Mount Lebanon and $v s$. the city of Sidon). For the group with sensory impairments, type and severity of impairment (partial hearing vs. total hearing, and vs. partial vision, and $v s$. total vision impairments) were also included as risk factors. The third phase of the analysis was logistic regression analyses. Two dependent variables were investigated, namely, exposure to severe trauma and development of PTSD and for the two study groups. Stepwise logistic regression analyses were conducted in view of more than one risk factor significantly related to the outcome variable in the bivariate analyses. The logistic regressions tested whether variables that were significant when tested alone remained significantly related to the outcome variable when used simultaneously with other risk factors.

\section{Results}

\section{Description of the study groups}

The majority of the group with sensory impairments had hearing impairments (77.3\%), and $39.8 \%$ of these adolescents had a partial hearing impairment compared to partial visual impairment in $55.3 \%$ of adolescents with visual impairments. The mean age for the group with impairments was 13.9 years $(\mathrm{SD}=2.5)$, and 13.9 years for the able-bodied group ( $\mathrm{SD}=2.1$ ). Males constituted $39.8 \%$ of each study group. The head of household was the father in $87.9 \%$ of the group with impairments compared to $88.0 \%$ in the able-bodied group. Further, the group with impairments belonged predominantly to manual social classes (66.7\%) as compared to $50.3 \%$ in the able-bodied group. As for geographical region, most of the study subjects attended schools in Mount Lebanon (57.8\%), followed by Greater Beirut (38.0\%), and the city of Sidon in South Lebanon (4.2\%). In fact, this reflects the geographic distribution of institutions that cater for the educational needs for adolescents with impairments, their preponderance being in Mount Lebanon. 28

\section{Exposure to traumatic events}

Exposure to severe traumatic events in the two study groups is presented in Table 1. For adolescents with sensory impairments, the most common traumatic events were close exposure to bombing and shelling, death of others, being injured, and other war events. For their able-bodied peers, bombing and shelling were the most prevalent, followed by war events, injury of others and destruction or theft of one's own home. For respondents with sensory impairments, $24.1 \%$ reported exposure to a traumatic event that fit the PTSD stressor definition as compared to 69.9 among the ablebodied group (Table 1).

The distribution of PTSD sum score by exposure to severe trauma for the two study groups is are presented in a box plot in Figure 1. Severe trauma was categorized into four broad categories: death, injury to self or other, shelling, and other war events. For the disabled

Table 1. Prevalence of exposure to main traumatic event.

\begin{tabular}{lcccc}
\hline Event & \multicolumn{2}{c}{$\begin{array}{c}\text { Adolescents with } \\
\text { sensory impairments }\end{array}$} & \multicolumn{2}{c}{$\begin{array}{c}\text { Able-bodied } \\
\text { adolescents }\end{array}$} \\
& $\mathbf{N}$. & $\%$ & 50 & 30.1 \\
Bombing and shelling & 11 & 6.6 & 5 & 3.0 \\
Death of others & 10 & 6.0 & 7 & 4.2 \\
\hline Injured & 6 & 3.6 & 17 & 10.2 \\
War event & 4 & 2.4 & 6 & 3.6 \\
\hline Death of relative & 2 & 1.2 & 9 & 5.4 \\
Destruction/theft of home & 2 & 1.2 & 9 & 5.4 \\
\hline Injury of relative & 1 & 0.6 & 1 & 0.6 \\
Injury of others & 1 & 0.6 & 0 & 0 \\
\hline Personal incident & 1 & 0.6 & 2 & 1.2 \\
Displacement & 1 & 0.6 & 1 & 0.6 \\
\hline Other & 1 & 0.6 & 5 & 3.0 \\
Death of close family member & - & - & 4 & 2.4 \\
\hline Injury of close family member & - & - & 116 & 69.9 \\
\hline Total (traumatic events) & 40 & 24.1 & 50 & 30.1 \\
\hline No event & 126 & 75.9 & 166 & 100 \\
\hline Total & 166 & 100 &
\end{tabular}


group, it is noted that similar median scores for PTSD are noted across all four categories of trauma. For the able-bodied group, higher median scores and are noted for shelling and other war events and a lower mean score is noted for injury to self or others. Noteworthy here is that other war events include events whose nature the subjects did not wish to disclose. Comparing the two groups on PTSD sum scores and trauma categories, it is noted that the able-bodied group reported more extreme scores for shelling and other war events.

The results of the stepwise logistic regression for the disabled group showed that exposure to a stressor event was significantly lower in those younger than 13 years $(\mathrm{OR}=0.28$, $\mathrm{CI}=0.09-0.81$ ), among individuals with total visual impairment $(\mathrm{OR}=8.57, \mathrm{CI}=2.24-32.76)$, and among those whose household was not headed by their father $(\mathrm{OR}=4.83, \mathrm{CI}=1.51$ 15.44) (Table 2). For their able-bodied peers, results of the stepwise logistic regression showed that this exposure was significantly less common among those whose household is not headed by their father $(\mathrm{OR}=0.23, \mathrm{CI}=0.07$ $0.70)$. This exposure was also more common in those residing in Mount Lebanon $(\mathrm{OR}=4.33$, $\mathrm{CI}=2.68-12.73$ ), and less common is those residing in the city of Sidon $(\mathrm{OR}=0.11$, $\mathrm{CI}=0.01-0.03$ ) (Table 2).

\section{Prevalence of and risk factors for post traumatic stress disorders}

Of the 40 respondents with sensory impairments who reported exposure to traumatic events, 17.5\% developed PTSD, yielding a prevalence of $4.2 \%$ in the total group of adolescents with impairments. One risk factor for PTSD in this exposed group was identified by the stepwise logistic regression, namely, belonging to the age group younger than 13 years $(\mathrm{OR}=11.25, \mathrm{CI}=1.42-89.26)$ (Table 3$)$. For able-bodied adolescents, $16.4 \%$ of those exposed to a traumatic event had PTSD, for a prevalence rate of $11.4 \%$ in this group. No risk factors were identified for PTSD among the able-bodied group (Table 3).

\section{Discussion}

The purpose of this study was to investigate level of exposure to severe stressor events and subsequent development of PTSD among adolescents with sensory impairments and their able-bodied peers. This study also attempted to identify risk factors for exposure to these events and also for developing PTSD.

A major strength of this study is the pioneer investigation of the effect of political violence on adolescents with sensory disabilities, and the inclusion of all sensorially disabled adoles- cents in three geographical regions of the country. Limitations of this study include the fact that the group of adolescents with sensory impairments in this study may represent a select group who attended schools that cater for their needs as compared to a large segment of disabled people who did not have such an opportunity.29,30 Further, the PTSDRC scale was not used before with sensorially impaired subjects. However, there is reason to believe that the very simple wording of this scale that was devised for use with children made it appropriate for use in this study. Noteworthy is the fact that the institutions covered by the study catered only for adolescents with sensorial disabilities and not for adolescents with mixed disabilities such as having both a visual and a hearing disability or having a mental and a sensorial disability. Further, the cross-sectional design of the current study precluded any causal inference regarding the relationship between exposure to war events and its risk factors as well as relationships between PTSD and its risk factors.

Four main findings were noted in this study. The first showed that adolescents with sensory impairments reported lower exposure to severe traumas that qualify as PTSD stressors ( $24.1 \%$ vs. $69.90 \%$ in the able-bodied group). Results of studies of Lebanese adolescents in schools for the same time period reported prevalence rates of exposure to PTSD war stressors that ranged from $31.5 \%$ to $42.9 \% .4,31$ Reasons for a lower exposure to war trauma point to the social distance that is kept from people with disabilities minimizes their interaction with their non disabled peers. ${ }^{22}$ Implicit also is the fact that in times of shelling, kid-

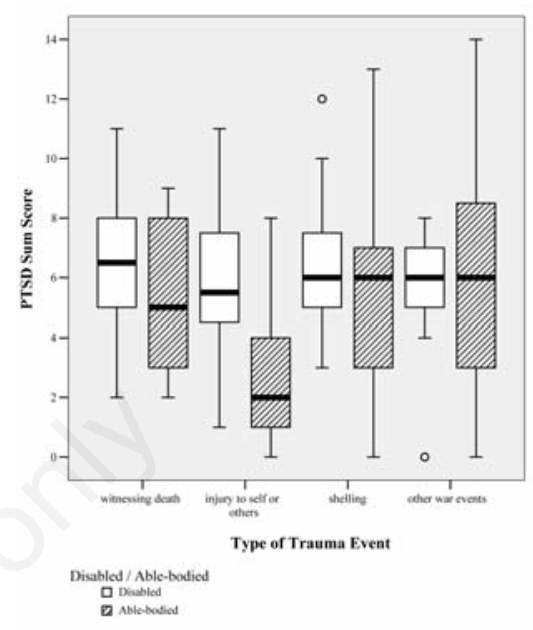

Figure 1. Box plot of traumatic event types and the PTSD sum score for disabled and able-bodied adolescent groups.

Table 2. Results of the stepwise logistic regression for exposure to trauma and selected explanatory variables.

\begin{tabular}{|c|c|}
\hline Risk factor & Odds ratio ( $95 \%$ C.I.) \\
\hline \multicolumn{2}{|c|}{ Adolescents with sensory impairments } \\
\hline Age (<13 years) & $0.28(0.09-0.81)^{*}$ \\
\hline $\begin{array}{l}\text { Severity and type of impairment } \\
\text { Partial hearing impairment } \\
\text { Total hearing impairment } \\
\text { Partial visual impairment } \\
\text { Total visual impairment } \\
\text { Head of household (not father) }\end{array}$ & $\begin{array}{c}1.00 \\
1.25(0.46-3.34) \\
1.58(0.43-5.87) \\
8.57(2.24-32.76)^{*} \\
4.83(1.51-15.44)^{*}\end{array}$ \\
\hline \multicolumn{2}{|c|}{ Able-bodied adolescents } \\
\hline Head of household (not father) & $0.23(0.07-0.70)^{*}$ \\
\hline $\begin{array}{l}\text { Region } \\
\text { Greater Beirut } \\
\text { Mount Lebanon } \\
\text { City of Sidon } \\
\end{array}$ & $\begin{array}{c}1.00 \\
4.33(1.93-9.69)^{* *} \\
0.11(0.01-0.93)^{*}\end{array}$ \\
\hline
\end{tabular}

Cl, confidence interval; ${ }^{*} \mathrm{P}<0.05,{ }^{*} \mathrm{P}<0.001$

Table 3. Results of the stepwise logistic regression for post traumatic stress disorder after exposure to trauma and selected explanatory variables.

Risk factor Odds ratio ( $95 \%$ C.I.)

Adolescents with sensory impairments

Age $(<13$ years $)$

$11.25(1.42-89.26)^{*}$

Able-bodied adolescents

C.I., confidence interval; $* \mathrm{P}<0.05$. 
napping and fighting, it is hard for visually disabled people to find their way around and are thus housebound. Able-bodied adolescents, on the other hand took an active part in war activities. Anecdotal evidence during data collection for this study showed that the able-bodied group was more likely to participate in war activities such as fighting or patrolling their neighborhoods while the group of disabled adolescents led a more sheltered life style. A pattern of active involvement and direct exposure to the armed conflict was also noted by Macksoud et al. ${ }^{31}$ in their investigation of the war experiences of Lebanese adolescents.

The second main finding was that rates of PTSD after exposure to trauma were similar in the two study groups (17.5\% and $16.4 \%$ in the disabled and able-bodied groups respectively). These PTSD rates were elevated when compared to rates among adolescents in peaceful countries such as the neighboring Oman (0.5\%) and the U.S. (8.0\%).32,33 Further, in this study, the prevalence of PTSD in the total sample was $4.2 \%$ in the group with disability and $11.4 \%$ in the able-bodied group. Lower PTSD rates in disabled adolescents were due to a lower exposure to trauma rather than a higher level of resilience as was hypothesized earlier. Other PTSD rates noted in another study of adolescents in schools in Lebanon, using the same DSMIII criteria and for the same time period were $46.7 \%$ in those exposed to war trauma and $14.7 \%$ in the total sample (4).

The third main finding showed different risk factors for exposure to trauma in the two study groups. For individuals with sensory impairments, older age, severe visual impair ment, and loss of father as head of household, were related to severe trauma exposure. Older age may signify more years of exposure to war. ${ }^{31}$ The father as head of household in a paternally oriented culture such as that of Lebanon is important in providing security and stability to the family. The loss of this figurehead for adolescents with disabilities may invoke feelings of vulnerability in a society known for its aversion to dealing with people with disabilities.22 For the able-bodied group, loss of father as head of household made the able-bodied adolescents more responsible for the family. In the able-bodied group, living in Mount Lebanon was also related to higher trauma exposure, an expected finding as severe bouts of fighting at the end of the Lebanese civil war occurred in these areas.

The fourth main finding was that among the study group, older age groups reported higher exposure levels to PTSD stressor events while younger age groups were at a higher risk of developing PTSD, which is in line with findings of other researchers. ${ }^{31,34}$ The vulnerabili ty of younger age groups to effects of severe stress may be explained by the fact that young children lack the cognitive abilities available to adults, and this limits their repertoire of adaptive responses and coping capabilities. ${ }^{34}$

\section{Conclusions}

In conclusion, results of this study showed lower exposure rates to severe trauma and similar PTSD rates in adolescents with sensory impairments when compared to their able-bodied peers. The investigated risk factors operated largely by predicting trauma exposure rather than development of PTSD. Disability has not made adolescents with impairments more resilient, but forced them into a more sheltered lifestyle.

\section{References}

1. Armenian, HK. In wartime: options for epidemiology. AJ Epidemiol 1986;124:28-32.

2. Bromet E, Sonnega A, Kessler RC. Risk factors for DSMIII-R posttraumatic stress disorder: findings from the national comorbidity study. Am J Epidemiol 1998;147: 353-61.

3. Breslau N, Kessler RC, Chilcaot HD, et al. Trauma and posttraumatic stress disorder in the community. The 1996 Detroit area survey of trauma. Arch Gen Psychiatry 1998;55:626-32.

4. Saigh PA, Mroueh A, Brenner JD. Scholastic impairments among traumatized adolescents. Behav Res Ther 1997;35:429-36.

5. Labre MM, Hadi F. Post-traumatic stress, anxiety and perceived stress. In: El-Amine A, ed. The psychological conditions of children and youth in Lebanon after the July 2006 war. Beirut: Lebanese Association for Educational Studies; 2008.

6. Karam E, Fayyad J, Salamoun M, et al. Assessment study of psychosocial status of children and adolescents in the South of Lebanon and southern suburbs of Beirut after the July 06 war (SSSS). Beirut: Institute for Development, Research, Advocacy and Applied Care; 2007.

7. Karam EG, Fayyad J, Karam AN, et al. Effectiveness and specificity of a classroom-based group intervention in children and adolescents exposed to war in Lebanon. World Psychiatry 2008;7:105-9.

8. Khamis V. Impact of war, religiosity, and ideology on PTSD and psychiatric disorders in adolescents from Gaza Strip and South Lebanon. Soc Sci Med 2012;74:200511.

9. Ahmad A, von Knorring AL, SundelinWahsten V. Traumatic experiences and post-traumatic stress symptoms in
Kurdish children in their native county and in exile. Child Adol Ment Health 2008;13:193-7.

10. Ahmad A. Symptoms of posttraumatic stress disorder among displaced Kurdistani children in Iraq - victims of a man made disaster after the gulf war. Nordic J Psychiatry 1992:46:315-9.

11. Al Jawadi AA, Abdul-Rhman S. Prevalence of childhood and early adolescence mental disorders among children attending primary healthcare centers in Mosul, Iraq: a cross-sectional study. BMC Public Health 2007;7:274.

12. Al-Razakhi A, Taha IK, Taib NI, et al. Mental health of Iraqi children. Lancet 2006;368:838-9.

13. Nader KO, Pynoos RS, Fairbanks LA, AlAjeel M. A preliminary study of PTSD and grief among children of Kuwait following the Gulf crisis. Brit J Clin Psychol 1993; 32:40-416.

14. Schwarzwald J, Weiseberg M, Waysman M, et al. Stress reaction of school-age children to the bombardment by SCUD missiles. J Abnorm Psychol 1993;102:404-10.

15. Solomon Z, Lavi T. Israeli youth in the second Intifada: PTSD and future orientation. J Am Acad Child Adolesc Psychiatry 2005; 44:1167-75.

16. Abdeen Z, Qasrawi R, Nabil S, Shaheen M. Psychological reactions to Israeli occupation: Findings from the national study of school-based screening in Palestine. Inter J Behav Dev 2008;32:290-7.

17. Elbedour S, Onwuegbuzie AJ, Ghannoum $\mathrm{J}$, et al. Post-traumatic stress disorder, depression and anxiety among Gaza Strip adolescents in the wake of the second uprising (Intifada). Child Abuse Neglect 2007;37:719-29.

18. Quota S, Punamaki RL, El Sarraj E. Prevalence and determinants of PTSD among Palestinian children exposed to military violence. Eur Child Adolesc Psychiatry 2003;12:265-72.

19. Thabet AAM, Abed Y, Panos V. Comorbidity of PTSD and depression among refugee children during war conflict. J Child Psychol Psyc 2004;45:533-42.

20. Khamis V. Post-traumatic stress disorder among school children age Palestinian children. Child Abuse Neglect 2005;29:8195.

21. Groce NE. Adolescents and youth with disability: issues and challenges. Asia Pac Rehab J 2004;15:13-32.

22. Shaar KH, McCarthy M. Social distance from people with disabilities in a city at war. Med War 1994;10:133-7.

23. Cardozo BL, Bilukha ML, Anderson M. Mental health, social functioning and disability in postwar Afghanistan. JAMA 2004;292:575-84. 
24. Office of Population Censuses and Surveys. Classification of occupations. London: HMSO; 1980.

25. Shaar KH, McCarthy M. Disadvantage as a measure of handicap: a paired sibling study of disabled adults in Lebanon. Intern J Epidemiol 1992;22:101-7.

26. Macksoud M, Aber L, Dyregrov A, Raundalen M. Post-traumatic stress reaction checklist for children. New York: Columbia University: Center for the Study of Human Rights, Project on Children and War; 1990.

27. American Psychiatric Association, Committee on Nomenclature and Statistics. Diagnostic and statistical manual of mental disorders. Third editionrevised. Washington DC: American Psychiatric Association; 1987.
28. Bryce J, Shaar KH, Shaya M, Jamal R. Child care institutions. In: Bryce J, Armenian HK, eds. In wartime: the state of children in Lebanon. Beirut: American University of Beirut; 1986: pp 61-97.

29. Shaar KH, Shaar R. The status of people with impairments in Lebanon: findings from a population-based survey. In: Shaar KH, McCarthy M, Shaar R, eds. Is there life after disability? Insights into the social context of disablement and disadvantage. Montreal: Alpha Books; 2002. pp 47-66.

30. Shaar KH, McCarthy M. Definitions and determinants of handicap in people with disabilities. Epidemiol Rev 1994;16:228-42.

31. Macksoud MS, Aber JL. The war experiences and psychological development of children in Lebanon. Child Dev 1996; 67:70-88.
32. Jaju S, A-Adawi $\mathrm{S}$, Al-Kharusi $\mathrm{H}$, et al. Prevalence and age-of-onset distributions of DSMIV mental disorders and their severity among school-going Omani adolescents and youths: WMH-CIDI findings. Child and Adoles Psychiatry Ment Health 2009;3:29.

33. McCart MR, Zajc K, Danielson CK, et al. Interpersonal victimization, posttraumatic stress disorder, and change in adolescent substance use. Prevalence over a ten year period. J Clin Child Adolec Psychol 2011; 40:136-43.

34. Jensen PS, Shaw J. Children as victims of war: current knowledge and future research needs. J Am Acad Child Adolesc Psychiatry 1993;32:697-708. 